\title{
Epidemiologic Evidence for Association between a High Dietary Acid Load and the Breast Cancer Risk
}

\author{
Alvaro L. Ronco ${ }^{1,2,3 *}$, Wilner Martínez-López ${ }^{4}$, Beatriz Mendoza ${ }^{5}$, \\ Juan M. Calderón ${ }^{3}$ \\ ${ }^{1}$ Unit of Oncology and Radiotherapy, Pereira Rossell Women's Hospital, Bvard. Artigas 1590, Montevideo 11600, Uruguay. \\ ${ }^{2}$ School of Medicine, CLAEH University, Prado and Salt Lake, Maldonado 20100, Uruguay. \\ ${ }^{3}$ Biomedical Sciences Center, University of Montevideo, Puntas de Santiago 1604, Montevideo 11500, Uruguay. \\ ${ }^{4}$ Epigenetics and Genomics Instability Laboratory and Biodosimetry Service, Instituto de Investigaciones Biológicas Clemente Estable, \\ Av. Italia 3318, Montevideo 11600, Uruguay. \\ ${ }^{5}$ Department of Endocrinology and Metabolism, School of Medicine, University of the Republic (UdelaR), Av.Italia s/n and Las Heras, \\ Montevideo 11600, Uruguay.
}

Received 08 February 2021; Revised 21 March 2021; Accepted 27 March 2021; Published 01 June 2021

\begin{abstract}
Background and Purpose: Dietary acid load contributes to metabolic acidosis, leading to inflammation and cell transformation, potentially implicated in cancer development. Albeit an increased risk of recurrence among BC survivors was reported for a high acid load, the epidemiologic evidence associating diet-dependent acid load and cancer risk, particularly for breast cancer (BC), is still very limited. Therefore, we have explored in the present study its role in BC risk. Methods: A case-control study was performed on 1461 patients $(572 \mathrm{BC}$ cases and 889 age-frequency matched controls), through a multi-topic questionnaire, which included a food frequency questionnaire. Food-derived nutrients were calculated from available databases. The dietary acid load was calculated based on existing measures as potential renal acid load (PRAL) score and net endogenous acid production (NEAP) score. Odds Ratios (ORs) and their 95\% confidence intervals were estimated by logistic regression, adjusting for potential confounders. Results: We found direct associations between dietary acid load and $\mathrm{BC}$ risk. Both scores were significantly associated $(\mathrm{OR}=2.46$ and $\mathrm{OR}=1.78$ for highest PRAL and NEAP, respectively). A positive BC family history involved higher risks ( $\mathrm{OR}=6.14$ and $\mathrm{OR}=3.38$ for highest PRAL and NEAP, respectively). Linear trends were found in all overall and stratified analyses. Conclusions: Results suggest that a low acid load dietary style may reduce BC risk since both PRAL and NEAP scores were directly associated with meat intake and inversely associated with plant-based foods intake. The findings agree with studies focused on food groups and dietary patterns. Further studies are needed to confirm these findings.
\end{abstract}

Keywords: Acid Load; Breast Cancer; Diet; Epidemiology; Nutrition.

\section{Introduction}

Breast cancer (BC) is the leading malignancy among Uruguayan women [1], with the highest incidence rate in South America and close to North American pictures [2, 3]. An independent effect of modifiable risk factors as dietary patterns, lifestyle factors, macro- and micronutrient intake, physical activity, tobacco smoking, and weight gain on the

* Corresponding author: alv.ronco58@gmail.com

do) http://dx.doi.org/10.28991/SciMedJ-2021-0302-8

$>$ This is an open access article under the CC-BY license (https://creativecommons.org/licenses/by/4.0/).

(C) Authors retain all copyrights. 
$\mathrm{BC}$ risk was highlighted in several studies [4]. Among the nutritional items that may reduce the BC risk, particularly those that tend to be aggressive tumors, are fruits and vegetables, specifically cruciferous and yellow/orange vegetables [5]. Conversely, Western-like dietary patterns have gained some relevance linked to its risk association [6]. The quoted patterns usually involve a high meat intake, which is considered a potential risk factor for BC [7, 8]. Uruguay is a developing country; nevertheless, its human development index is high [9], and its average diet is meatbased, with the world's highest per capita beef intake [10]. In this respect, the associations between meat and BC in Uruguay were initially explored more than two decades ago $[11,12]$.

Blood $\mathrm{pH}$ is maintained within the range of 7.35-7.45 and tends to be rapidly controlled by the body's buffer systems to avoid acidosis $(\mathrm{pH}<7.35)$ or alkalosis $(\mathrm{pH}>7.45)$. Minimal changes are expected in the value of plasma bicarbonate, and blood $\mathrm{pH}$ within the range considered normal [13]. When the $\mathrm{pH}$ is balanced at values close to the lower limit (7.35), this condition is called low-grade metabolic acidosis. Some factors can lead to low-grade metabolic acidosis, and diet is one of the main factors that may influence the occurrence of this condition [14]. In particular, a long-term high protein consumption (e.g., from Western-like dietary patterns) can induce it. [15, 16]

Metabolic acidosis can be calculated through the potential renal acid load (PRAL) [15] and net endogenous acid production (NEAP) [16] formulas, which are validated and straightforward methods to estimate the dietary acid load from diet-composition data. A prolonged diet-induced low-grade metabolic acidosis over the years may predispose to metabolic abnormalities, in particular, insulin resistance, diabetes, high serum triglycerides, and obesity [17, 18]. Consequently, the production of insulin-like growth factor-1 (IGF-I) probably increases [19], which, in turn, is associated with an increased BC risk [20].

A recent prospective study suggested that a higher diet-dependent acid load is associated with an increased risk of invasive BC. Conversely, alkaline diets or diets lower in diet-dependent acid load may be protective, especially for Estrogen Receptor-negative BC [21]. Nevertheless, there is limited and inconsistent epidemiologic evidence on the association between diet-dependent acid load and BC risk [22], focused on its incidence and recurrence risk [21, 2325]. Therefore, we decided to explore possible associations of diet-dependent acid load and the risk of BC among Uruguayan women. To our knowledge, the present study is the first Latin American case-control study that analyzes dietary acid load and BC risk.

\section{Material and Methods}

We combined two databases previously used in epidemiologic studies on BC in the Uruguayan population [26-29]. Those studies were carried out in Uruguay during 1996-2004 in Montevideo's principal public hospitals (Pasteur, Maciel, Clinicas, Oncology Institute) and one private hospital. Formal consents were not required for this type of study at that time. The studies were conducted after being authorized by Directors receiving ethical approval in each participant institution. With a similar structure, both databases enabled us to study a total sample of 1461 participants (572 BC cases, 889 controls). Each one is briefly described as follows and the flowchart in Figure 1 summarizes the methodology of both studies.

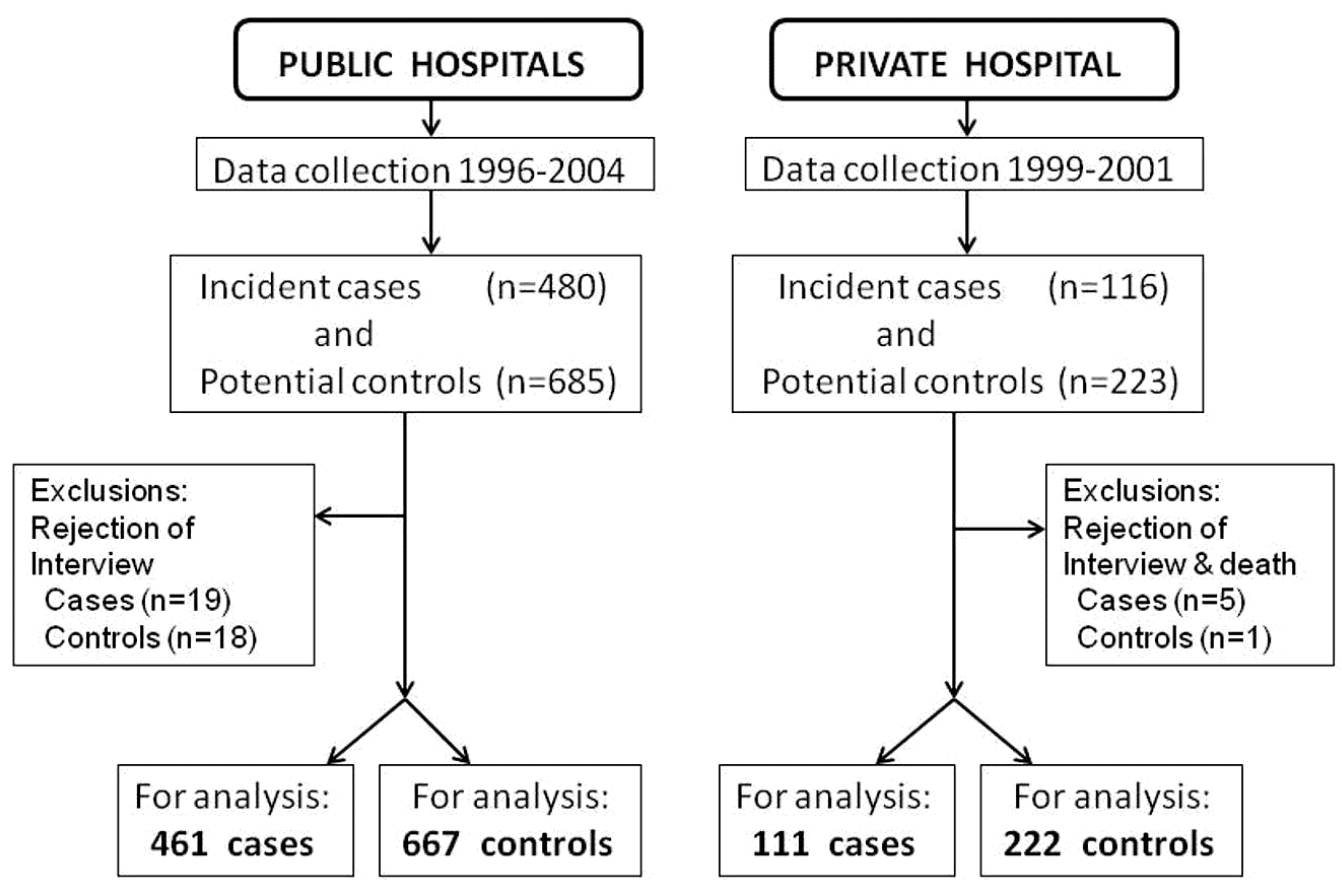

Figure 1. Flowchart summarizing each study's sequences 


\subsection{Public Hospitals}

As part of multi-site epidemiologic research, 480 incident $\mathrm{BC}$ cases were eligible for the study period. Nineteen patients rejected an interview, leaving 461 cases to be included (response rate $96.0 \%$ ). In the same period and hospitals, 685 admitted patients afflicted with diseases unrelated to smoking and drinking were eligible for the study. Eighteen patients rejected the interview, leaving 667 controls (response rate 97.4\%). Trained social workers, unaware of the study objectives, worked at the hospitals in two phases: First, they looked routinely for newly diagnosed cancer patients, working with Medical Records personnel's collaboration. Second, they contacted patients who were eligible to be matched by the age-frequencies of the cases, as well as their urban/rural residence, and their regions (Montevideo/Other counties). After obtaining consent for the study, all the participants underwent an in-person interview in the hospitals. No proxy interviews were conducted. According to Uruguayan law, patients admitted to public hospitals were people with low incomes, from the whole country, and free access to medical services. Considering the population's features, they were good representatives of a third world country, different from the community admitted at the private health institution.

A 2:1 ratio for controls/cases was projected, but external economic factors determined budgetary cuts during the early 2000s and further. Consequently, a perfect matching was not possible to be completed.

\subsection{Private Hospital}

An epidemiologic study on BC conducted in 1999-2001 at a pre-paid medical institution in Montevideo (IMPASA) derived 116 incident BC cases and 223 controls women having normal mammography (BI-RADS 1) [30] $\leq 1$ year before the interview. One control and two cases refused the interview, and three cases were excluded for medical reasons, finally achieving 111 cases and 222 controls (response rates: $95.7 \%$ and 99.6\% respectively). They were age-matched ( \pm five years). All participants, inhabitants of Montevideo (the capital city), did not remain at the hospital during the interviews. Women were $<85$ years old and belonged to mid-to-high socioeconomic strata. After appointments made by phone, interviews were face-to-face conducted in a hospital's office by a trained nurse blinded by major risk factors.

\subsection{Interviews and Questionnaire}

Participants answered a structured questionnaire which included: socio-demographic variables; occupation; BC history in $1^{\circ}-2^{\circ}$ degree relatives; self-reported height and weight five years before the interview; smoking and alcohol; a history of "mate," tea and coffee drinking; menstrual-reproductive events; and a food frequency questionnaire (FFQ) of 64 items, representative of Uruguayan diet, focused on food consumption five years before the interview. Proxy interviews were not accepted. The FFQ was not validated; however, it was tested for reproducibility [31], allowing individual energy estimation. All dietary questions were open-ended. Local tables of food composition were used for estimating energy and nutrients [32].

\subsection{Estimation of Dietary Acid Load}

We calculated the diet-dependent acid load using previously defined formulas [15, 16] and applied in other epidemiologic studies on BC risk [21, 25] as well as on recurrence [23, 24]: potential renal acid load (PRAL) and net endogenous acid production (NEAP). These measurements were calculated as follows:

$\operatorname{PRAL}(\mathrm{mEq} /$ day $)=(0.49 \times$ total protein $[\mathrm{g} /$ day $])+(0.037 \times$ phosphorus $[\mathrm{mg} /$ day $])-(0.021 \times$ potassium $[\mathrm{mg} / \mathrm{day}])-$ $(0.026 \times$ magnesium $[\mathrm{mg} /$ day $])-(0.013 \times$ calcium $[\mathrm{mg} /$ day $]) ;$

$\operatorname{NEAP}(\mathrm{mEq} / \mathrm{day})=(54.5 \times \operatorname{protein}[\mathrm{g} / \mathrm{day}]) /(0.0256 \times \operatorname{potassium}[\mathrm{mg} / \mathrm{day}])-10.2 ;$

The PRAL score takes into account the intestinal absorption rates for protein, potassium, calcium, magnesium, and phosphate and has been validated against urine $\mathrm{pH}$ in healthy adults [15]. The rate of sulfuric acid production from protein metabolism and the rate of bicarbonate generation from metabolism of intestinally absorbed potassium salts of organic acids are major and highly variable components of the NEAP score, developed by Frassetto et al. [16]. These authors stated that "by considering both, the acidifying effect of protein and the alkalinizing effect of potassium (organic anions), NEAP can be predicted with confidence from the readily available contents of only 2 nutrients in foods." In addition, they found that PRAL and NEAP were highly correlated $(r=0.84, p<0.001)$. A negative PRAL or NEAP value reflects an alkaline-forming potential, whereas a positive value reflects an acid-forming potential.

An analysis program was compiled to calculate energy, which made the sum of all individual values. Each one was obtained after multiplying the number of servings/year by the ratio calories of the serving/100 $\mathrm{g}$ of each, divided by 365 days. Most typical or average servings of solid foods are within the range of 100-150 g. Since iron intake showed a high correlation with energy, we calculated an iron density expressed as daily $\mathrm{mg}$ of the mineral/kcal*1000. 


\subsection{Statistical Analysis}

The questionnaire variables were initially continuous. When necessary, they were categorized for analysis purposes. Aside from primary descriptive analyses (frequencies, mean values), we calculated Odds Ratios (ORs) and $95 \%$ confidence intervals $(95 \% \mathrm{CI})$ by unconditional logistic regression [33]. Terms for potential confounders were included in the multivariate analyses. The equations included terms for: age (categorical), residence (binary), education (categorical), age at menarche (categorical), menopausal status (binary), age at first live birth (categorical), number of live births (categorical), age at menopause (categorical), family history of BC (binary), BMI (continuous), smoking intensity in pack-years (continuous), alcohol status (categorical) and energy intake (categorical) as independent variables, and cancer (yes/no) as the dependent one. Possible heterogeneities in the stratified analyses were explored through likelihood-ratio tests. The STATA software was used to make all calculations (Release 10 StataCorp LP, College Station, TX, 2007).

\section{Results}

Table 1 shows the distribution of cases and controls according to selected socio-demographic variables. Although participants were not completely matched, an adequate age distribution was achieved $(\mathrm{p}=0.87)$. There were more rural cases than controls (12.9\% vs. 9.4\%, resp.). Most traditional BC risk factors (family history of cancer, reproductive variables) displayed significant or marginal differences between cases and controls. On the other hand, educational level and BMI did not.

Table 1. Distribution of sociodemographic and selected reproductive variables in cases and controls

\begin{tabular}{|c|c|c|c|c|c|c|}
\hline \multirow[t]{2}{*}{ Variables } & \multirow{2}{*}{$\begin{array}{c}\text { Categories } \\
\leq 49\end{array}$} & \multicolumn{2}{|c|}{ Controls \% $(\mathrm{n}=\mathbf{8 8 9})$} & \multicolumn{2}{|c|}{ Cases \% $(n=572)$} & \multirow[t]{2}{*}{ Global p-value } \\
\hline & & 200 & 22.5 & 123 & 21.5 & \\
\hline \multirow{3}{*}{ Age groups } & $50-59$ & 223 & 25.1 & 143 & 25.0 & \multirow{3}{*}{0.94} \\
\hline & $60-69$ & 243 & 27.3 & 155 & 27.1 & \\
\hline & $\geq 70$ & 223 & 25.1 & 151 & 26.4 & \\
\hline \multirow{2}{*}{ Health system } & Public & 667 & 75.0 & 461 & 80.6 & \multirow{2}{*}{0.01} \\
\hline & Private & 222 & 25.0 & 111 & 19.4 & \\
\hline \multirow{3}{*}{ Education years } & $\leq 6$ & 551 & 62.0 & 359 & 62.8 & \multirow{3}{*}{0.94} \\
\hline & $7-12$ & 223 & 25.1 & 142 & 24.8 & \\
\hline & $\geq 13$ & 115 & 12.9 & 71 & 12.4 & \\
\hline \multirow{2}{*}{ Residence } & Urban & 805 & 90.5 & 498 & 87.1 & \multirow{2}{*}{0.03} \\
\hline & Rural & 84 & 9.4 & 74 & 12.9 & \\
\hline \multirow{3}{*}{$\begin{array}{l}\text { Body Mass Index } \\
\qquad\left(\mathrm{kg} / \mathrm{m}^{2}\right)\end{array}$} & $\leq 24.99$ & 389 & 43.8 & 238 & 41.6 & \multirow{3}{*}{0.54} \\
\hline & 25.0-29.99 & 327 & 36.8 & 210 & 36.7 & \\
\hline & $\geq 30.0$ & 173 & 19.5 & 124 & 21.7 & \\
\hline \multirow{2}{*}{ Fam.History of BC } & No & 811 & 91.2 & 450 & 78.7 & \multirow{2}{*}{$<0.001$} \\
\hline & Yes & 78 & 8.8 & 122 & 21.3 & \\
\hline \multirow{2}{*}{ Menopausal status } & Pre & 182 & 20.5 & 97 & 17.0 & \multirow{2}{*}{0.09} \\
\hline & Post & 707 & 79.5 & 475 & 83.0 & \\
\hline \multirow{4}{*}{ Age of menarche } & $\leq 11$ & 207 & 23.3 & 138 & 24.1 & \multirow{4}{*}{0.09} \\
\hline & 12 & 273 & 30.7 & 145 & 25.3 & \\
\hline & 13 & 175 & 19.7 & 136 & 23.8 & \\
\hline & $\geq 14$ & 234 & 26.3 & 153 & 26.7 & \\
\hline \multirow{3}{*}{$\mathrm{N}^{\mathrm{o}}$ of live births } & Nulliparous & 111 & 12.5 & 104 & 18.2 & \multirow{3}{*}{0.006} \\
\hline & $1-2$ & 394 & 44.3 & 252 & 44.1 & \\
\hline & $\geq 3$ & 384 & 43.2 & 216 & 37.8 & \\
\hline \multirow{3}{*}{ Age at $1^{\text {st }}$ live birth } & $\leq 20$ & 281 & 36.1 & 150 & 32.0 & \multirow{3}{*}{0.054} \\
\hline & $21-26$ & 304 & 39.1 & 173 & 37.0 & \\
\hline & $\geq 27$ & 193 & 24.8 & 145 & 31.0 & \\
\hline \multirow{3}{*}{$\begin{array}{l}\text { Breastfeeding time } \\
\quad \text { (total months) }\end{array}$} & $\leq 3$ & 283 & 31.8 & 218 & 38.1 & \multirow{3}{*}{0.03} \\
\hline & $4-15$ & 307 & 34.5 & 168 & 29.4 & \\
\hline & $\geq 16$ & 299 & 33.6 & 186 & 32.5 & \\
\hline
\end{tabular}


Some selected lifestyle variables were analyzed and presented in Table 2. Energy, red meat, and alcohol intake were directly and significantly associated with BC risk. On the other hand, fruits, vegetables, and the three infusions (coffee, tea, and 'mate') were inversely and significantly associated with the risk.

Table 2. Crude Odds Ratios (OR) of selected consumptions linked to lifestyle. Comparisons between highest vs. lowest categories

\begin{tabular}{|c|c|c|c|c|c|}
\hline Variable & Categories & Controls /cases & Global p-value & OR (95\% CI) & p-value for trend \\
\hline \multirow{4}{*}{$\begin{array}{c}\text { Red meat } \\
\text { (servings/year) }\end{array}$} & $\leq 112$ & $254 / 101$ & \multirow{4}{*}{$<0.001$} & \multirow{4}{*}{$3.58(2.62-4.88)$} & \multirow{4}{*}{$<0.001$} \\
\hline & $113-183$ & $256 / 118$ & & & \\
\hline & $184-290$ & $228 / 138$ & & & \\
\hline & $\geq 291$ & $151 / 215$ & & & \\
\hline \multirow{4}{*}{$\begin{array}{c}\text { Fruits } \\
\text { (units/year) }\end{array}$} & $\leq 218$ & 207/159 & \multirow{4}{*}{0.006} & \multirow{4}{*}{$0.67(0.49-0.90)$} & \multirow{4}{*}{0.001} \\
\hline & $219-365$ & $204 / 159$ & & & \\
\hline & $366-844$ & $236 / 130$ & & & \\
\hline & $\geq 845$ & $242 / 124$ & & & \\
\hline \multirow{4}{*}{$\begin{array}{c}\text { Vegetables } \\
\text { (servings/year) }\end{array}$} & $\leq 400$ & $190 / 173$ & \multirow{4}{*}{$<0.001$} & \multirow{4}{*}{$0.67(0.50-0.90)$} & \multirow{4}{*}{0.003} \\
\hline & $401-620$ & $226 / 141$ & & & \\
\hline & $621-905$ & $245 / 118$ & & & \\
\hline & $\geq 906$ & $228 / 140$ & & & \\
\hline \multirow{4}{*}{$\begin{array}{c}\text { Energy } \\
\text { (Kcal/day) }\end{array}$} & $\leq 1625$ & $244 / 121$ & \multirow{4}{*}{0.02} & \multirow{4}{*}{$1.58(1.17-2.14)$} & \multirow{4}{*}{0.002} \\
\hline & $1626-1944$ & $225 / 140$ & & & \\
\hline & $1945-2288$ & $215 / 150$ & & & \\
\hline & $\geq 2289$ & $205 / 161$ & & & \\
\hline \multirow{2}{*}{$\begin{array}{c}\text { Coffee } \\
\text { (Consumption) }\end{array}$} & Never & $607 / 431$ & \multirow{2}{*}{0.004} & \multirow{2}{*}{$0.70(0.56-0.89)$} & \multirow{2}{*}{0.004} \\
\hline & Ever & $282 / 141$ & & & \\
\hline \multirow{2}{*}{$\begin{array}{c}\text { Tea } \\
\text { (Consumption) }\end{array}$} & Never & $503 / 386$ & \multirow{2}{*}{0.02} & \multirow{2}{*}{$0.77(0.62-0.95)$} & \multirow{2}{*}{0.02} \\
\hline & Ever & $360 / 212$ & & & \\
\hline \multirow{3}{*}{$\begin{array}{l}\text { 'Mate' intake } \\
\text { (ml/day) }\end{array}$} & None & $146 / 108$ & \multirow{3}{*}{$<0.001$} & \multirow{3}{*}{$0.59(0.43-0.79)$} & \multirow{3}{*}{$<0.001$} \\
\hline & $\leq 999$ & $308 / 275$ & & & \\
\hline & $\geq 1000$ & $435 / 189$ & & & \\
\hline \multirow{2}{*}{$\begin{array}{l}\text { Alcohol } \\
\text { Status }\end{array}$} & Non drinker & $759 / 451$ & \multirow{2}{*}{0.001} & \multirow{2}{*}{$1.57(1.19-2.06)$} & \multirow{2}{*}{0.001} \\
\hline & Ever drinker & $130 / 121$ & & & \\
\hline Smoking & Non smoker & $659 / 409$ & 027 & $114(000145)$ & 027 \\
\hline Status & Ever smoker & $230 / 163$ & 0.27 & $1.14(0.90-1.45)$ & 0.21 \\
\hline
\end{tabular}

Table 3 displays the mean values of PRAL and NEAP scores and their components comparing cases and controls. Both mean scores were higher among BC cases. Regarding the details, differences in protein and phosphorus intakes were significantly higher among cases. However, potassium, magnesium, and calcium intakes were not significantly different between cases and control groups.

Table 3. Mean daily values \pm standard deviation of the acid load scores and their components. Stratification of items according to their animal/plant original source. Comparison between cases and controls

\begin{tabular}{|c|c|c|c|c|}
\hline Variable & Units & $\begin{array}{l}\text { CONTROLS } \\
\text { Mean } \pm \text { SD }\end{array}$ & $\begin{array}{c}\text { CASES } \\
\text { Mean } \pm \text { SD }\end{array}$ & Diff.(p) \\
\hline Total Proteins & $\mathrm{g}$ & $109.6 \pm 49.6$ & $118.8 \pm 42.3$ & 0.0001 \\
\hline Total proteins/energy & $\mathrm{g} / 10^{3} \mathrm{Kcal}$ & $56.2 \pm 14.1$ & $57.3 \pm 12.8$ & 0.14 \\
\hline Animal proteins/energy & $\mathrm{g} / 10^{3} \mathrm{Kcal}$ & $51.7 \pm 14.2$ & $53.2 \pm 12.9$ & 0.04 \\
\hline Total Phosphorus & $\mathrm{mg}$ & $759.6 \pm 256.9$ & $776.2 \pm 265.5$ & 0.23 \\
\hline Total phosphorus/energy & $\mathrm{mg} / 10^{3} \mathrm{Kcal}$ & $389.9 \pm 76.4$ & $374.3 \pm 70.9$ & 0.0001 \\
\hline Animal phosphorus/energy & $\mathrm{mg} / 10^{3} \mathrm{Kcal}$ & $246.3 \pm 70.4$ & $241.3 \pm 62.0$ & 0.16 \\
\hline Plant phosphorus/energy & $\mathrm{mg} / 10^{3} \mathrm{Kcal}$ & $143.6 \pm 45.1$ & $133.1 \pm 45.3$ & $<0.0001$ \\
\hline
\end{tabular}




\begin{tabular}{lcccc}
\hline Total Potassium & $\mathrm{mg}$ & $2051.5 \pm 678.5$ & $2062.5 \pm 754.7$ & 0.77 \\
Total potassium/energy & $\mathrm{mg} / 10^{3} \mathrm{Kcal}$ & $1064.7 \pm 258.6$ & $1000.4 \pm 247.3$ & $<0.0001$ \\
Animal potassium/energy & $\mathrm{mg} / 10^{3} \mathrm{Kcal}$ & $379.4 \pm 94.4$ & $385.3 \pm 91.3$ & 0.24 \\
Plant potassium/energy & $\mathrm{mg} / 10^{3} \mathrm{Kcal}$ & $685.3 \pm 242.9$ & $615.2 \pm 242.4$ & $<0.0001$ \\
\hline Total Magnesium & $\mathrm{mg}$ & $178.8 \pm 59.2$ & $179.0 \pm 65.8$ & 0.95 \\
Total magnesium/energy & $\mathrm{mg} / 10^{3} \mathrm{Kcal}$ & $92.5 \pm 20.8$ & $86.7 \pm 20.9$ & $<0.0001$ \\
Animal magnesium/energy & $\mathrm{mg} / 10^{3} \mathrm{Kcal}$ & $27.7 \pm 6.7$ & $27.7 \pm 6.1$ & 0.96 \\
Plant magnesium/energy & $\mathrm{mg} / 10^{3} \mathrm{Kcal}$ & $64.8 \pm 20.2$ & $59.0 \pm 20.7$ & $<0.0001$ \\
\hline Total Calcium & $\mathrm{mg}$ & $854.2 \pm 425.0$ & $817.3 \pm 466.4$ & 0.12 \\
Total calcium/energy & $\mathrm{mg} / 10^{3} \mathrm{Kcal}$ & $437.0 \pm 192.4$ & $391.6 \pm 181.4$ & $<0.0001$ \\
Animal calcium/energy & $\mathrm{mg} / 10^{3} \mathrm{Kcal}$ & $222.4 \pm 165.9$ & $193.7 \pm 153.1$ & 0.0009 \\
Plant calcium/energy & $\mathrm{mg} / 10^{3} \mathrm{Kcal}$ & $214.6 \pm 69.9$ & $197.9 \pm 74.6$ & $<0.0001$ \\
\hline PRAL & $\mathrm{mEq}$ & $22.6 \pm 21.7$ & $29.7 \pm 23.2$ & $<0.0001$ \\
\hline NEAP & $\mathrm{mEq}$ & $84.9 \pm 31.3$ & $90.9 \pm 32.3$ & 0.004 \\
\hline
\end{tabular}

Table 4 displays the adjusted ORs for both acid load scores. The highest vs. lowest quartile of PRAL derived a significant estimate $(\mathrm{OR}=2.46)$ with a highly significant trend ( $\mathrm{p}$ trend <.001). The same applies to the NEAP score: both risk and trend estimates were significant $(\mathrm{OR}=1.78, \mathrm{p}$ trend <.001). The analyses stratified by family history of $\mathrm{BC}$ showed higher risks with a positive history: PRAL had an OR=6.14 ( $\mathrm{p}$ trend <.001), and NEAP had an OR=3.38 (p trend $=.001)$.

Table 4. Adjusted Odds Ratios (ORs) of BC for acid load scores (PRAL and NEAP), with global estimations and stratified analyses by menopausal status and family history of $\mathrm{BC}$

\begin{tabular}{|c|c|c|c|c|c|}
\hline \multicolumn{6}{|c|}{ SCORE LEVELS } \\
\hline & $\mathbf{I}$ & II & III & IV & \\
\hline & OR $95 \%$ CI & OR $95 \%$ CI & OR $95 \% \mathrm{CI}$ & OR $95 \%$ CI & \\
\hline PRAL (mEq/d) & $\leq 12.1$ & $12.2-22.7$ & $22.8-34.9$ & $>34.9$ & Trend (p) \\
\hline Cases/Controls & $111 / 254$ & $120 / 246$ & $160 / 204$ & $181 / 185$ & \\
\hline All & $1.00 \quad---$ & $1.01 \quad 0.73-1.40$ & $1.76 \quad 1.28-2.42$ & $2.46 \quad 1.76-3.44$ & $<0.001$ \\
\hline Prem & $1.00 \quad---$ & $0.99 \quad 0.43-2.27$ & $2.26 \quad 0.97-5.25$ & $\mathbf{3 . 3 3} 1.41-7.89$ & 0.002 \\
\hline Postm & $1.00 \quad---$ & $1.02 \quad 0.72-1.46$ & $\mathbf{1 . 7 1} 1.21-2.41$ & $2.31 \quad 1.61-3.33$ & $<0.001$ \\
\hline FH No & $1.00 \quad---$ & $0.88 \quad 0.61-1.25$ & $1.621 .15-2.27$ & $2.121 .48-3.04$ & $<0.001$ \\
\hline FH Yes & $1.00 \quad---$ & $2.06 \quad 0.93-4.52$ & $2.97 \quad 1.22-7.23$ & $6.14 \quad 2.30-16.4$ & $<0.001$ \\
\hline NEAP (mEq/d) & $\leq 68.0$ & 68.1-82.4 & $82.5-99.2$ & $>99.2$ & Trend (p) \\
\hline Cases/Controls & $122 / 244$ & $122 / 243$ & $157 / 208$ & $171 / 194$ & \\
\hline All & $1.00 \quad---$ & $0.98 \quad 0.72-1.35$ & $1.56 \quad 1.15-2.13$ & $1.78 \quad 1.30-2.42$ & $<0.001$ \\
\hline Prem & $1.00 \quad---$ & $0.76 \quad 0.34-1.71$ & $1.39 \quad 0.65-2.98$ & $1.49 \quad 0.69-3.26$ & 0.14 \\
\hline Postm & $1.00 \quad---$ & $1.00 \quad 0.71-1.42$ & $1.63 \quad 1.16-2.29$ & $1.82 \quad 1.29-2.56$ & $<0.001$ \\
\hline FH No & $1.00 \quad---$ & $0.97 \quad 0.69-1.36$ & $\mathbf{1 . 4 3} \quad 1.03-2.00$ & $1.58 \quad 1.13-2.22$ & 0.001 \\
\hline FH Yes & $1.00 \quad---$ & $1.05 \quad 0.47-2.32$ & $2.64 \quad 1.12-6.19$ & $3.38 \quad 1.41-8.11$ & 0.001 \\
\hline
\end{tabular}

* The equations included terms for: age (categorical), residence (binary), education (categorical), age at menarche (categorical), menopausal status (binary), age at first live birth (categorical), number of live births (categorical), age at menopause (categorical), family history of BC (binary), BMI (continuous), smoking intensity in packyears (continuous), alcohol status (categorical) and energy intake (categorical) as independent variables, and cancer (yes/no) was the dependent one.

** Likelihood ratio tests for heterogeneity were: non-significant for Menopausal status $(\mathrm{p}=0.72$ ) and significant for Family history of $\mathrm{BC}$ ( $\mathrm{p}=0.03$ ).

***Abbreviations: Prem=premenopausal; Postm=postmenopausal; $\mathrm{FH}=$ family history of breast cancer in relatives of $1^{\text {st }}$ and $2^{\text {nd }}$ degree together.

**** Bold letters indicate statistically significant values

\section{Discussion}

We found direct associations between dietary acid load and BC risk. The ORs for the highest vs. lowest quartile were significant regarding both scores employed and their linear trends: PRAL (OR=2.54, ptrend $<0.001)$ and NEAP $(\mathrm{OR}=1.78$, ptrend $<0.001)$. Stratified analyses done in a recent prospective study [21] found suggestively stronger 
associations between PRAL and BC in women who had a sister diagnosed with BC before age 50 years, especially for ER-negative BC. Albeit we had no data on ages of relatives' cancer cases nor hormonal receptors of patients, our stratified analyses by family history also showed a risk increase for PRAL score when this history was present, compared to its absence ( $\mathrm{OR}=6.14$ vs. $\mathrm{OR}=2.12$, respectively). Besides, the NEAP score displayed similar associations ( $\mathrm{OR}=3.38$ vs. $\mathrm{OR}=1.58$, respectively). Having found significant heterogeneity between the absence/ presence of BC family history, this might imply gene-dietary interactions to be considered for future studies.

The existing epidemiologic evidence related to acid load and cancer risk is limited, restricted to BC [21, 23, 25], colorectum [34, 35], and pancreas [36]. The research works related to BC are not consistent enough [21, 23-25]. There were positive associations for acid load with BC risk among American and Puerto Rican women [21, 23], but it was not associated among Iranian ones [25]. Some studies reported results about the influence of the acid load on the metabolic condition (hyperinsulinism and/or diabetes) [34, 35] and the association with BC recurrence and survival $[23,24]$. One of these, identified acid load as a novel dietary factor that may lead to inflammation and hyperglycemia [23]. Therefore, a dietary acid load may contribute to inflammation in cancer patients.

It has been claimed that dietary acid load can contribute to metabolic acidosis if the acid-base balance is not correctly adjusted. Metabolic acidosis is a condition characterized by a slight decrease in blood $\mathrm{pH}$ [14], and feeding is one of the main factors to produce such a situation. In humans, arterial and venous blood have a $\mathrm{pH}$ of 7.35-7.4 and 7.20-7.35, respectively [37]. Besides, there is growing evidence showing that the fluid $\mathrm{pH}$ in the interstitial space around metabolic tissues is easily reduced due to weaker $\mathrm{pH}$ buffering capacity than that in the cytosol and blood circulation. Whereas the arterial blood $\mathrm{pH}$ is strictly regulated due to strong $\mathrm{pH}$ buffers such as albumin and hemoglobin, interstitial fluids have only relatively weak $\mathrm{pH}$ buffers, bicarbonate, and phosphate, enabling a $\mathrm{pH}$ range of 6.60-7.60 [38]. Such interstitial pH reduction might initiate a metabolic dysfunction [39]. In contrast, several nutrients bring benefits in maintaining the interstitial fluid $\mathrm{pH}$ within the normal range by improving buffering capacities, suppressing proton production, and activating proton transporters, strengthening the effect of appropriate diet on metabolic health [38].

The excessive consumption of acid precursor foods (such as meat, cheese, and eggs, which are sources of phosphorus and proteins) leads to acid-base balance volubility. If this situation occurs in a prolonged, or chronic way, low-grade metabolic acidosis can become significant and predispose to metabolic imbalances. [13, 14, 40] Regarding these points, it is well known that metabolic acidosis can cause tissue damage, which can further initiate inflammation [23]. Inflammatory process induces oxidative stress and reduces cellular antioxidant capacity. Overproduction of free radicals reacts with cell membrane fatty acids and proteins, impairing their function permanently. Besides, free radicals can lead to gene mutation and DNA damage that predispose to the development of cancer and age-related disorders [41].

Cancer patients have reduced capabilities for adjusting their acid-base balance [42]. Several metabolic adaptations observed in cancer are recognized as similar to the perturbations observed in diabetic patients [37]. Albeit acidity has more than one source [43], the lactate derived from cancer cells suppresses T cell and NK cell function [44]. Moreover, metformin -an insulin sensitizer- frequently used to reduce hyperglycemia in diabetic patients, has been accepted to reduce cancer incidence [45] and improve survival [46].

An adequate intake of phosphorus for adults in the general population is $550 \mathrm{mg} / \mathrm{day}$. However, European countries' mean intake is higher than 2-fold such value (1000-1767 mg/day) [47]. By the same token, our study population sample showed a mean intake of $766 \mathrm{mg} /$ day $(760 \mathrm{mg} / \mathrm{day}$ among controls $)$, which is higher than the adequate consumption, based on the quoted reference numbers. Dietary phosphorus has increased over time [48], mainly due to phosphorus-containing additives in food manufacturing and processing [49]. Furthermore, there is evidence that cellular phosphate burden from phosphate toxicity is a pathophysiological determinant of cancer cell growth [50]. According to these authors, a dysregulated phosphate homeostasis can be associated with the genesis of various human tumors.

Besides, a diet that includes phosphorus-enhanced foods can probably add another 600-800 mg to the overall daily intake and non-negligible amounts of sodium chloride $(\mathrm{NaCl})$ [51]. Indeed, its intake is reported to be an independent predictor of plasma bicarbonate concentration. $\mathrm{NaCl}$ may exert approximately $50-100 \%$ of the acidosis-producing effect of the dietary acidic load and is considered a predictor of diet-induced low-grade metabolic acidosis [52]. Besides, an increasing $\mathrm{NaCl}$ dose-dependently decreases blood $\mathrm{pH}$ and plasma bicarbonate levels, independent of the partial pressure of $\mathrm{CO}_{2}$, creatinine clearance, and dietary acid load. [13] On the other hand, potassium, magnesium, and calcium are precursors of bases. Therefore, the main foods that release precursors of acids into the bloodstream are mostly of animal sources, and foods that are precursors of bases are mainly those of plant sources [14]. Table 3 shows the components of acid load scores, discriminated by animal/plant source, as it has been previously discussed.

In addition to dietary phosphorus, or to the use of phosphorus-containing additives, the picture turns even more complicated when it was taken into account the previous relationships among acid load, chronic inflammation, and 
oxidative stress: The interaction of free radicals with polyunsaturated fatty acids of cell membrane causes lipid peroxidation and subsequent cell damage, leading to leakage of intracellular phosphorus into serum [53]. Therefore, Western-like dietary patterns may enhance a vicious cycle involving lipoperoxidation, inflammation, and metabolic acidosis.

Potential diet-gene interactions involving hormonal mechanisms, susceptibility genes, polymorphisms, and epigenetic regulatory mechanisms could be present regarding the dietary acid load and BC. In addition, some links have been uncovered between cancer and circadian disruption, in particular related to BC [54]. Recent research discovered a profound disruption of the circadian clock and diurnal transcriptome when hypoxic cells are permitted to acidify to recapitulate the tumor microenvironment [55]. These authors also found that buffering against acidification or inhibiting lactic acid production fully rescues circadian oscillation.

As for the study's strengths, cases and controls were face-to-face, directly interviewed by the same trained personnel in the same hospital settings, and the studied population included subsets coming from the whole country and belonged to different socio-economic-cultural strata. Besides, times of data collection were coincident.

On the other hand, the present study may share some biases that are common to case-control studies. Withinperson variability over the study period may be a source of information bias. Selection bias was limited by the nearly full participation of the identified cases and controls (rates $97 \%$ ), favored by the interview during the hospital stay. Dietary habits were relatively stable in the Uruguayan population, and patients were asked to report any relevant dietary changes occurring during their life. Furthermore, a recall bias related to dietary habits should be negligible in our study population, as the awareness of BC's dietary hypothesis was very limited. Although the FFQ was not validated, it was satisfactorily reproducible [31]. Mineral estimations become one of the limitations of the present study since they were based on average serving sizes rather than actual food sizes. Besides, we could not exclude confounders' role by other dietary factors, such as other constituents of animal foods, the effects of different cooking methods, and the mineral contents in water. For example, highly processed and manufactured foods, which involve the use of phosphorus-containing additives, were not included in the FFQ. Therefore, no estimations of phosphorus and sodium from these potential sources were carried out.

\section{Conclusion}

Both calculated dietary acid load scores (PRAL and NEAP) were found directly and significantly associated with $\mathrm{BC}$ risk. The risk increase was seen irrespective of menopausal status, and it appeared to be more robust having a positive BC family history. Results suggest that a low acid load dietary style may reduce BC risk since both PRAL and NEAP scores were directly associated with meat intake -which characterize westernized dietary styles- and inversely associated with plant-based foods intake - which characterize Mediterranean and vegetarian-like styles-. The findings agree with studies focused on food groups and dietary patterns. Potential diet-gene interactions involving hormonal mechanisms, susceptibility genes, polymorphisms, and epigenetic regulatory mechanisms could be present regarding the dietary acid load and BC. Dietary and nutritional optimization, for example, regarding the achievement of a better dietary potassium/sodium ratio, is still not a highly emphasized area of health care. However, it has a great potential to attenuate the impact of prevalent chronic diseases in modern society (including BC) and improve population health [56]. In light of the implications of dietary acid load, although further studies are needed to confirm the present study's findings, we are convinced that from a medical and ethical viewpoint, it is justified to recommend -as we did one decade ago [57]- certain nutritional changes to women, because in the meantime no adverse side effects are expected to occur.

\section{Declarations}

\subsection{Author Contributions}

A.R. was responsible of the conceptualization, investigation, methodology, data analysis, draft writing, visualization, and final review and editing. W.M.L. participated in the visualization, the draft writing, and final review and editing. B.M. and J.M.C. participated in the draft writing, the final review and editing. All authors have read and agreed to the published version of the manuscript.

\subsection{Funding}

The authors received no financial support for the research, authorship, and/or publication of this article.

\subsection{Ethical Approval}

Each hospital Director has authorized the project after receiving the approval from the respective Ethical Committee. In past years (1990-2005), only oral consent was required from the patients, assuming the confidentiality 
about their data, and no specific code was formally requested for epidemiologic observational studies. An autogenerated number was built based on initials (first and last name + ID number) to preserve anonymity.

\subsection{Data Availability Statement}

The data presented in this study are available on request from the corresponding author.

\subsection{Conflict of Interest}

The authors declare that they have no known competing financial interests or personal relationships that could have appeared to influence the work reported in this paper.

\section{References}

[1] Barrios, E., Garau, M., Alonso, R., \& Musetti, C. (2014). IV Atlas of cancer incidence in uruguay. comision honoraria de lucha contra el cancer, montevideo, uruguay. (In Spanish)

[2] Sung, H., Ferlay, J., Siegel, R. L., Laversanne, M., Soerjomataram, I., Jemal, A., \& Bray, F. (2021). Global cancer statistics 2020: GLOBOCAN estimates of incidence and mortality worldwide for 36 cancers in 185 countries. CA: A Cancer Journal for Clinicians. doi:10.3322/caac.21660

[3] International Agency for Research on Cancer, 2018, Global Cancer Observatory-Cancer Today. Available online: https:// gco.iarc.fr/today/online-analysis-table. (accessed 11 June 2020).

[4] Mahmoud, R. I., \& Tayyem, R. F. (2020). Dietary and Lifestyle Factors and Breast Cancer Risk. Current Nutrition \& Food Science, 16(3), 251-259. doi:10.2174/1573401315666181129121258.

[5] Farvid, M. S., Chen, W. Y., Rosner, B. A., Tamimi, R. M., Willett, W. C., \& Eliassen, A. H. (2018). Fruit and vegetable consumption and breast cancer incidence: Repeated measures over 30 years of follow - up. International Journal of Cancer, 144(7), 1496-1510. doi:10.1002/ijc.31653

[6] Dianatinasab, M., Rezaian, M., HaghighatNezad, E., Bagheri-Hosseinabadi, Z., Amanat, S., Rezaeian, S., ... Ghiasvand, R. (2020). Dietary Patterns and Risk of Invasive Ductal and Lobular Breast Carcinomas: A Systematic Review and Meta-analysis. Clinical Breast Cancer, 20(4), e516-e528. doi:10.1016/j.clbc.2020.03.007

[7] Lo, J. J., Park, Y. M., Sinha, R., \& Sandler, D. P. (2019). Association between meat consumption and risk of breast cancer: Findings from the Sister Study. International Journal of Cancer, 146(8), 2156-2165. doi:10.1002/ijc.32547

[8] Clinton, S. K., Giovannucci, E. L., \& Hursting, S. D. (2019). The World Cancer Research Fund/American Institute for Cancer Research Third Expert Report on Diet, Nutrition, Physical Activity, and Cancer: Impact and Future Directions. The Journal of Nutrition, 150(4), 663-671. doi:10.1093/jn/nxz268.

[9] United Nations Development Program. Available online: http://hdr.undp.org/en/content/2019-human-development-indexranking (accessed on 1 September 2020).

[10] Food and Agriculture Organization, 2019, Available online: http://www.fao.org/faostat/en/\#data/CL (Accessed 28 July 2019 ).

[11] Ronco, A., De Stefani, E., Mendilaharsu, M., \& Deneo - Pellegrini, H. (1996). Meat, fat and risk of breast cancer: a case control study from Uruguay. International journal of cancer, 65(3), 328-331. doi: 10.1002/(SICI)10970215(19960126)65:3<328::AID-IJC9>3.0.CO;2-1.

[12] De Stefani, E., Ronco, A., Mendilaharsu, M., Guidobono, M., \& Deneo-Pellegrini, H. (1997). Meat intake, heterocyclic amines, and risk of breast cancer: a case-control study in Uruguay. Cancer Epidemiology and Prevention Biomarkers, 6(8), 573-581.

[13] Pizzorno, J., Frassetto, L. A., \& Katzinger, J. (2009). Diet-induced acidosis: is it real and clinically relevant? British Journal of Nutrition, 103(8), 1185-1194. doi:10.1017/s0007114509993047.

[14] Carnauba, R., Baptistella, A., Paschoal, V., \& Hübscher, G. (2017). Diet-Induced Low-Grade Metabolic Acidosis and Clinical Outcomes: A Review. Nutrients, 9(6), 538. doi:10.3390/nu9060538.

[15] Remer, T., \& Manz, F. (1994). Estimation of the renal net acid excretion by adults consuming diets containing variable amounts of protein. The American Journal of Clinical Nutrition, 59(6), 1356-1361. doi:10.1093/ajcn/59.6.1356.

[16] Frassetto, L. A., Todd, K. M., Morris, R. C., \& Sebastian, A. (1998). Estimation of net endogenous noncarbonic acid production in humans from diet potassium and protein contents. The American Journal of Clinical Nutrition, 68(3), 576-583. doi:10.1093/ajen/68.3.576.

[17] Kiefte-de Jong, J. C., Li, Y., Chen, M., Curhan, G. C., Mattei, J., Malik, V. S., ... Hu, F. B. (2016). Diet-dependent acid load and type 2 diabetes: pooled results from three prospective cohort studies. Diabetologia, 60(2), 270-279. doi:10.1007/s00125016-4153-7. 
[18] Abbasalizad Farhangi, M., Nikniaz, L., \& Nikniaz, Z. (2019). Higher dietary acid load potentially increases serum triglyceride and obesity prevalence in adults: An updated systematic review and meta-analysis. PLOS ONE, 14(5), e0216547. doi:10.1371/journal.pone.0216547.

[19] Robey, I. F. (2012). Examining the relationship between diet-induced acidosis and cancer. Nutrition \& Metabolism, 9(1), 72. doi:10.1186/1743-7075-9-72.

[20] Fürstenberger, G., \& Senn, H.-J. (2002). Insulin-like growth factors and cancer. The Lancet Oncology, 3(5), $298-302$. doi:10.1016/s1470-2045(02)00731-3.

[21] Park, Y. M., Steck, S. E., Fung, T. T., Merchant, A. T., Elizabeth Hodgson, M., Keller, J. A., \& Sandler, D. P. (2018). Higher diet - dependent acid load is associated with risk of breast cancer: Findings from the sister study. International Journal of Cancer, 144(8), 1834-1843. doi:10.1002/ijc.31889.

[22] Fenton, T. R., \& Huang, T. (2016). Systematic review of the association between dietary acid load, alkaline water and cancer. BMJ Open, 6(6), e010438. doi:10.1136/bmjopen-2015-010438.

[23] Wu, T., Seaver, P., Lemus, H., Hollenbach, K., Wang, E., \& Pierce, J. P. (2019). Associations between Dietary Acid Load and Biomarkers of Inflammation and Hyperglycemia in Breast Cancer Survivors. Nutrients, 11(8), 1913. doi:10.3390/nu11081913.

[24] Wu, T., Hsu, F.-C., Wang, S., Luong, D., \& Pierce, J. P. (2020). Hemoglobin A1c Levels Modify Associations between Dietary Acid Load and Breast Cancer Recurrence. Nutrients, 12(2), 578. doi:10.3390/nu12020578.

[25] Safabakhsh, M., Imani, H., Yaseri, M., Omranipour, R., \& Shab - Bidar, S. (2020). Higher dietary acid load is not associated with risk of breast cancer in Iranian women. CANCER REPORTS, 3(2). doi:10.1002/cnr2.1212.

[26] Ronco, A. L., De Stefani, E., Mendoza, B., Deneo-Pellegrini, H., Vazquez, A., \& Abbona, E. (2016). Mate Intake and Risk of Breast Cancer in Uruguay: a Case-Control Study. Asian Pacific Journal of Cancer Prevention, 17(3), $1453-1461$. doi:10.7314/apjcp.2016.17.3.1453.

[27] Ronco, A. L., Vazquez, A., Ronco, A., Stefani, E. D., Mendoza, B., Vazquez, A., ... \& Rosa, A. (2016). Mate and tea intake, dietary antioxidants and risk of breast cancer: a case-control study. Asian Pacific Journal of Cancer Prevention, 17(6), 29232933.

[28] Ronco, A. L., Calderon, J. M., \& Espinosa, E. (2017). Dietary iron,'mate'intake and breast cancer risk: a case-control study in Uruguay. J Breast Cancer Res Adv, 1(1), 1-7.

[29] Ronco, A. L., Espinosa, E., \& Calderón, J. M. (2018). A case-control study on heme/non-heme iron and breast cancer risk. Annals of Clinical Nutrition, 3, 1011.

[30] Sickles, E. A., d’Orsi, C. J., Bassett, L. W., Appleton, C. M., Berg, W. A., \& Burnside, E. S. (2013). Acr bi-rads® mammography. ACR BI-RADS ${ }^{\circledR}$ atlas, breast imaging reporting and data system, 5, 39-48.

[31] Ronco, A. L., De Stefani, E., Boffetta, P., Deneo - Pellegrini, H., Acosta, G., \& Mendilaharsu, M. (2006). Food patterns and risk of breast cancer: a factor analysis study in Uruguay. International journal of cancer, 119(7), 1672-1678. doi: 10.1002/ijc. 22021 .

[32] Mazzei ME, Puchulu MR, Rochaix MA. (1995) Table of food chemical composition. Cenexa y Feiden Publishers, 2nd Ed., Buenos Aires (in Spanish).

[33] Breslow, N. E., Day, N. E., \& Schlesselman, J. J. (1982). Statistical methods in cancer research. Volume 1-The analysis of case-control studies. Journal of Occupational and Environmental Medicine, 24(4), 255-257.

[34] . Ronco AL, Martínez-López W, Calderón JM, Mendoza BA. (2020) Dietary acid load and colorectal cancer risk: a casecontrol study. World Cancer Research Journal; 7: e1750. doi: 10.32113/wcrj_202011_1750.

[35] Jafari Nasab, S., Rafiee, P., Bahrami, A., Rezaeimanesh, N., Rashidkhani, B., Sohrab, G., ... Sadeghi, A. (2020). Dietdependent acid load and the risk of colorectal cancer and adenoma: a case-control study. Public Health Nutrition, 1-8. doi:10.1017/s1368980020003420.

[36] Shi, L.-W., Wu, Y.-L., Hu, J.-J., Yang, P.-F., Sun, W.-P., Gao, J., ... Zhong, G.-C. (2021). Dietary Acid Load and the Risk of Pancreatic Cancer: A Prospective Cohort Study. Cancer Epidemiology Biomarkers \& Prevention. doi:10.1158/1055-9965.epi20-1293.

[37] Gillies, R. J., Pilot, C., Marunaka, Y., \& Fais, S. (2019). Targeting acidity in cancer and diabetes. Biochimica et Biophysica Acta (BBA) - Reviews on Cancer, 1871(2), 273-280. doi:10.1016/j.bbcan.2019.01.003.

[38] Aoi, W., Zou, X., Xiao, J. B., \& Marunaka, Y. (2019). Body Fluid pH Balance in Metabolic Health and Possible Benefits of Dietary Alkaline Foods. eFood, 1(1), 12. doi:10.2991/efood.k.190924.001. 
[39] Marunaka, Y. (2018). The Proposal of Molecular Mechanisms of Weak Organic Acids Intake-Induced Improvement of Insulin Resistance in Diabetes Mellitus via Elevation of Interstitial Fluid pH. International Journal of Molecular Sciences, 19(10), 3244. doi:10.3390/ijms19103244.

[40] Osuna-Padilla, I. A., Leal-Escobar, G., Garza-García, C. A., \& Rodríguez-Castellanos, F. E. (2019). Dietary acid load: Mechanisms and evidence of its health repercussions. Nefrología (English Edition), 39(4), $343-354$. doi:10.1016/j.nefroe.2019.08.001.

[41] Khansari, N., Shakiba, Y., \& Mahmoudi, M. (2009). Chronic Inflammation and Oxidative Stress as a Major Cause of AgeRelated Diseases and Cancer. Recent Patents on Inflammation \& Allergy Drug Discovery, 3(1), 73-80. doi:10.2174/187221309787158371.

[42] Sia, P., Plumb, T. J., \& Fillaus, J. A. (2013). Type B Lactic Acidosis Associated With Multiple Myeloma. American Journal of Kidney Diseases, 62(3), 633-637. doi:10.1053/j.ajkd.2013.03.036.

[43] Lee, S.-H., \& Griffiths, J. R. (2020). How and Why Are Cancers Acidic? Carbonic Anhydrase IX and the Homeostatic Control of Tumour Extracellular pH. Cancers, 12(6), 1616. doi:10.3390/cancers12061616.

[44] Brand, A., Singer, K., Koehl, G. E., Kolitzus, M., Schoenhammer, G., Thiel, A., ... Kreutz, M. (2016). LDHA-Associated Lactic Acid Production Blunts Tumor Immunosurveillance by $\mathrm{T}$ and NK Cells. Cell Metabolism, 24(5), 657-671. doi:10.1016/j.cmet.2016.08.011.

[45] Yu, H., Zhong, X., Gao, P., Shi, J., Wu, Z., Guo, Z., ... Song, Y. (2019). The Potential Effect of Metformin on Cancer: An Umbrella Review. Frontiers in Endocrinology, 10. doi:10.3389/fendo.2019.00617.

[46] Dulskas, A., Patasius, A., Linkeviciute-Ulinskiene, D., Zabuliene, L., Urbonas, V., \& Smailyte, G. (2019). Metformin increases cancer specific survival in colorectal cancer patients-National cohort study. Cancer Epidemiology, 62, 101587. doi:10.1016/j.canep.2019.101587.

[47] European Food Safety Authority (EFSA) Panel on Dietetic Products, Nutrition and Allergies (NDA). (2015). Scientific Opinion on Dietary Reference Values for phosphorus. EFSA Journal, 13(7). doi:10.2903/j.efsa.2015.4185.

[48] Ritz, E., Hahn, K., Ketteler, M., Kuhlmann, M. K., \& Mann, J. (2012). Phosphate Additives in Food. Deutsches Aerzteblatt Online. doi:10.3238/arztebl.2012.0049.

[49] Hannah, J., Roe, M., Warthon-Medina, M., Pinchen, H., Barrett, M., \& Perry, S. (2018). Phosphorus in food: limitations of food composition data. Journal of Kidney Care, 3(6), 362-367. doi:10.12968/jokc.2018.3.6.362.

[50] Brown, R. B., \& Razzaque, M. S. (2018). Phosphate toxicity and tumorigenesis. Biochimica et Biophysica Acta (BBA) Reviews on Cancer, 1869(2), 303-309. doi:10.1016/j.bbcan.2018.04.007.

[51] Carrigan, A., Klinger, A., Choquette, S. S., Luzuriaga-McPherson, A., Bell, E. K., Darnell, B., \& Gutiérrez, O. M. (2014). Contribution of Food Additives to Sodium and Phosphorus Content of Diets Rich in Processed Foods. Journal of Renal Nutrition, 24(1), 13-19.e1. doi:10.1053/j.jrn.2013.09.003.

[52] Frassetto, L. A., Morris, R. C., \& Sebastian, A. (2007). Dietary sodium chloride intake independently predicts the degree of hyperchloremic metabolic acidosis in healthy humans consuming a net acid-producing diet. American Journal of PhysiologyRenal Physiology, 293(2), F521-F525. doi:10.1152/ajprenal.00048.2007.

[53] Pavithra, V. (2015). Serum Levels of Metal Ions in Female Patients with Breast Cancer. Journal of Clinical and Diagnostic Research. doi:10.7860/jcdr/2015/11627.5476.

[54] Lin, H.-H., \& Farkas, M. E. (2018). Altered Circadian Rhythms and Breast Cancer: From the Human to the Molecular Level. Frontiers in Endocrinology, 9. doi:10.3389/fendo.2018.00219.

[55] Walton, Z. E., Patel, C. H., Brooks, R. C., Yu, Y., Ibrahim-Hashim, A., Riddle, M., .. Dang, C. V. (2018). Acid Suspends the Circadian Clock in Hypoxia through Inhibition of mTOR. Cell, 174(1), 72-87.e32. doi:10.1016/j.cell.2018.05.009.

[56] Qian, Q. (2018). Dietary Influence on Body Fluid Acid-Base and Volume Balance: The Deleterious "Norm" Furthers and Cloaks Subclinical Pathophysiology. Nutrients, 10(6), 778. doi:10.3390/nu10060778.

[57] Ronco, A. L., De Stéfani, E., \& Stoll, M. (2010). Hormonal and metabolic modulation through nutrition: Towards a primary prevention of breast cancer. The Breast, 19(5), 322-332. doi:10.1016/j.breast.2010.05.005. 